\title{
Comparison of Base Shears Estimated from Floor Accelerations and Column Shears
}

\author{
Rakesh K. Goel, ${ }^{\text {a) }}$ Y.EERI
}

This paper compares base shears computed from floor accelerations (inertial base shear) and column shears (structural base shear) for two mid-rise, multistory buildings due to a suite of 30 earthqualce ground motions. The presented results demonstratc that the inertial base shear exceeds the structural base shear in the median by $10 \%$ to $20 \%$ and may exceed the structural base shear by as much as $70 \%$ for individual ground motions. Therefore, it is concluded that the inertial base shear computed from strong motion records should be used with caution to estimate the structural base shcar. [DOI: 10.1193/1.3610247]

\section{INTRODUCTION}

Buildings are typically instrumented with accelerometers at a selected number of floors: low-rise buildings (one to three stories) at every floor; and mid- and high-rise buildings at base, roof, and a few intemediate floors. The accelerations at instrumented floors are interpolated (e.g., Naeim, 1997, Naeim et al. 2004, Goel 2005, Limongelli 2003) to estimate accelerations at remaining floors, which are then used to estimate base shear by adding all floor inertial forces above the base (Figure 1a); the inertial force at a floor is computed as the product of floor acceleration and foor mass (e.g., Jennings 1997, Naeim 1997). The base shear computed using the aforementioned procedure is referred to as the "inertial base shear" in the rest of this paper and is denoted by $V_{h d}$ in the longitudinal direction and $V_{b y}$ in the transverse direction. It is useful to emphasize that this proccdure is an approximate method to obtain an estimate (not neccssarily an exact value) of the base shcar demand during an earthquake without the need for detailed structural analysis.

The inertial base shear demand is often compared with the base shear capacity, estimated from either pushover analysis (e.g., Gocl 2005) or the code design base shear (e.g., Naein 2004). The base shcar capacity from pushover analysis or the code hase shear is indicative of the sum of shear forces in all columns at the building's base (Figure 1b). The base shear defined by the aforementioned procedurc is referred to as the "structural base shear" in rest of this paper and is denoted by $V_{h x R}$ in the longitudinal direction and $V_{b y R}$ in the transverse dircetion.

$A$ large number of buildings are instrumented in seismically active regions such as California. The strong motion records obtained from such buildings during carthquake ground shaking are increasingly being used for making decisions about the nced for dctailed postearthquakc inspection of such buildings. One of the criteria triggering detailed inspection

\footnotetext{
a) Professor, Depattment of Civil and finvirmenental fingineering, California Polytechnic State University, San Luis Obispo, C^ $93407-0353$
} 


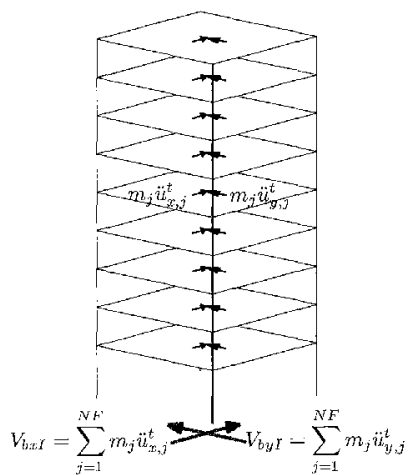

(a)

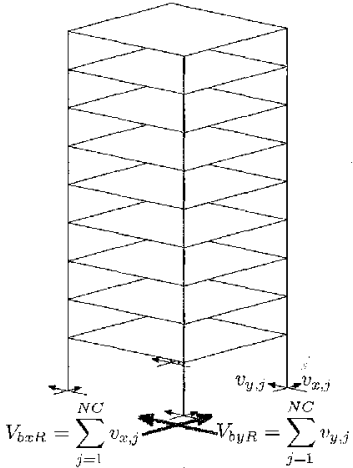

(b)

Figure 1. Computation of base shear: (a) Inertial base shear computed from sumunation of inertial floor forces and (b) structural base shear computed from sumbnation of column shears.

involyes comparing inertial base shear induced in the building during an earthquake ground shaking with its structural base shear capacity (or code design basc shear): if the inertial base shear exceeds the base shear capacity, the building is expected to have suffered damage requiring detailed inspection.

Observations from buildings that were strongly shaken during the 1994 Northridge earthquake indicate that inertial base shear may not always be a good indicator of damage in the building. For exanple, consider the performance of two buildings-the 20 -story reinforced-concrete hotel in North Hollywood and the 19-story steel office building in Los Angeles for which the inertial base shear demand excecded the base shear capacity (or code design basc shear) during the 1994 Northridge carthquake (Nacim 1998, Gocl 2009). Ilowever, post-earthquake inspection (Naeim 1997, 1998) indicated insignificant damage in the Noth Hollywood building (minor cracking in bean and columns) and minor damage in the Los Angeles building (bucking in a fow braces in up per stories). Clearly, these buildings were not deformed much beyond their linear elastic limits. This indicates that the inertial base shear should not have exceded the structural base shear if the inertial base sbear was a good approximation of the structural base shcar.

The apparent discrepancy noted above between peak inertial and structural base shears can be attributed to the following three factors. First, the crror may occur in estimation of peak inertial base shear because interpolation procedure used to estimate accelerations at non-instrumented floors may lead to inaccurate floor accelerations which in turn will lead to 
inaccurate floor inertial forces and inertial base shear. Second, the error may occur in cstimation of peak structural base shcar capacity from pushover analysis due to crrors associated with modeling and analytical assumptions. Third, discrepancy between inertial and struclural base shears occurs due to contribution of damping forces.

A comprehensive study to fully understand the contribution of each of the three factors requires that error corrcsponding to each factor be cxamined individually. This is possible only if the building is instrumented to measure accclerations at each floor and shears in all columns at its base. Clearly, such a study requires detailed laboratory experiments on well instrumented multistory buildings. Since experimental study is beyond the scope of this investigation, we rely on results from numerical simulations. For this purpose, responses (floor accelerations, column shears) of two buildings - the 20-story reinforced-concrete hotel in North Hollywood and the 19-story steel office building in I.os Angeles-are computed from nonlinear response history analysis (RILA) for a suite of 30 ground motions recorded during past earthquakes using the structural analysis software Perform $3 D$ (CSI 2006). The Perform3D computer models used FEMA-356 (ASCE 2000) recommendations for beam/column force-deformation behavior. Further details of these buildings, modeling techniques, and ground motions are available in Gocl $(2009,2010)$ and Gocl and Nishimoto (2009). The inertial and struetural base shears are then computed from the nonlinear RHA results and compared to demonstrate the difference between the two for multistory buildings.

It is useful to note that the approach used in this investigation eliminates the errors associated with interpolation of accelerations because accelerations are available at all floors. Furthermore, it also clininatcs the errors associated with modeling and analytical assumptions because both inertial base shear and structural hase shear are for the same model, albeit a computer model.

Recently, Bernal and Nasseri (2009) and Bernal (2010) investigated error in the hase shear duc to different interpolation procedures and presented Kalman Filter and Minimum Norm Response Corrector methods for minimizing this error. The base shear considered in these investigations was the inertial base shear because it was assumcd that the inertial base shear is generally a good approximation of the structural base shear (Bernal 2010). Thercfore, the error investigated in Bernal and Nasseri (2009) and Bemal (2010) is duc to interpolation procedures, which differs from the error between inertial and structural base shears being investigated in this paper.

\section{COMPARISON OF INERTIAL AND STRLCTURAL BASE SHEARS}

Compared in this section are the inertial and structural base shears in the two selected buildings due to the selected ground motions. It is useful to note that the ground motions in this investigation were not selected to match a particular design spectrum but to ensure that they will induce different levels of inelastic behavior in the selected buildings. It was found during analysis that the selected buildings experienced excessive deformation due to several of the ground motions and collapsed. Results for these ground motions have been excluded from those presented in this section.

Examined first were the time-variations of inertial and structural base shears for selected ground motions. This examination showed that the incrtial base shear matched the structural 

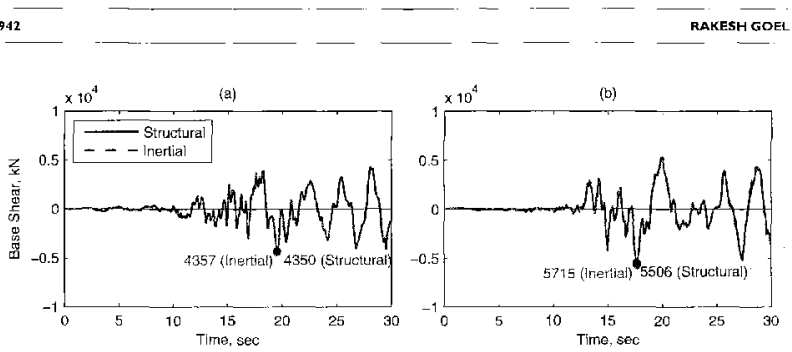

Figure 2. Companison of inertial and structural basc shears in the North Hollywood hotel for Earthquake No. 14: (a) Longitudinal direction and (b) transverse direction.

base shear quite well for some earthquakes but the difference was very large for others. Since the length limitation of this paper prohibits presentation of all results, selected results are presented for each of the two buildings in Figures 2 to 5 to denonstrate cases where the two base shears matched quite woll and where they differed significantly; results for other ground motions are available in Goel (2009).

The results for the North Hollywood hotel indicate that the incrtial base shear tracks the structural hase shear quite well for earthquake No. 14. Furthermore, the peak value of inertial base shear is essentially equal to the structural base shear in the longitudinal direction (Figure $2 \mathrm{a}$ ) and cxceeds the structural base shear by no more than $4 \%$ in the transverse direction (Figure $2 b$ ). While the inertial base shear tracks the structural basc shear quite well for earthquake No. 9 , the peak value may differ by about $10 \%$ in the longitudinal direction (Figure 3a) and by about $20 \%$ in the transverse direction (Figure 3b).

The results presented for the Los Angeles building indicates a very good match between inertial and structural base shears for earthquake No. 4 (Figure 4). For earthqualie No. I5.
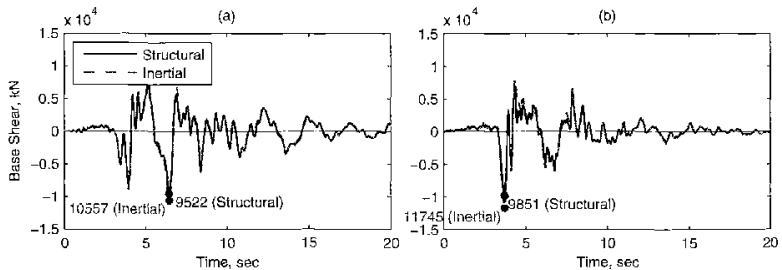

Figure 3. Comparison of inertial and structural base shears in the North Hollywond hotel for Farthquake No. 9: (a) Longitudinal direction and (b) transverse direction. 

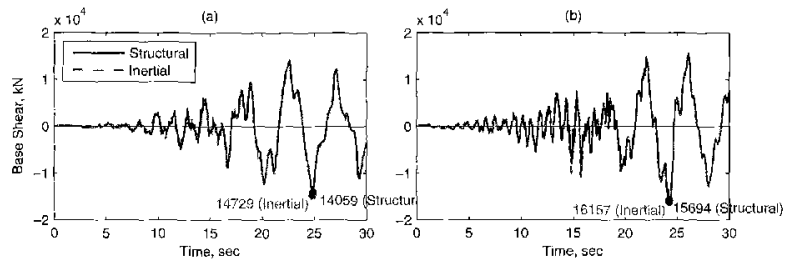

Figure 4. Comparison of inertiat and structural base shears in the I os Angeles building for Larthquake No. 4: (a) Longitudinal direetion and (b) transverse direction.

however, the inertial basc shear differs significantly from the structural base shcar not only in the peak value but in the frequency content as well (Figure 5). The peak value of inertial basc shear exceeds the structural base shear by about $70 \%$ in the longitudinal direction (Figure $5 \mathrm{a}$ ) and by about $35 \%$ in the transverse direction (Figure $5 \mathrm{~b}$ ). The results of Figure 5 also show that the inertial base shear has significant high-frequency content compared to the structural. base shear. Therefore, it appears that the inertial base sbear may significantly exceed the structural base shear for ground motions with significant high-frequency content.

Examined next are the ratios, $V_{b x I} / V_{b x R}$ and $V_{b y I} / V_{b y R}$, of the inerlial and structural base shears for the two buildings. The results are presented in Figures 6 and 7 for earthquakes for whicb the building did not to collapse. The presented results include ratios for individual earthquakes along with the median values.

The results presented in Figure 6 for the Noth llollywood hotel show that the ratio $V_{b i} / V_{b R}$ for some carthquakes can bc as high as 1.2 . This indicates that incrtial base shcar may exceed the structural base shear by up $1020 \%$. The median value of the ratio is,
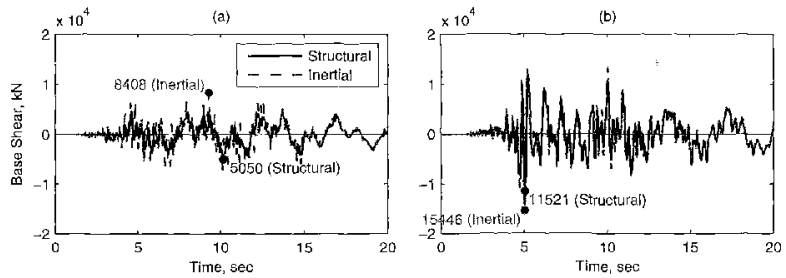

Figure 5. Comparison of inertial and structural base shcars in the Los Angeles building for Earthquake No. 15: (a) Longitudinal direction and (b) transverse direction. 
(a)

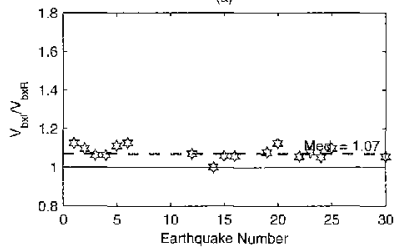

(b)

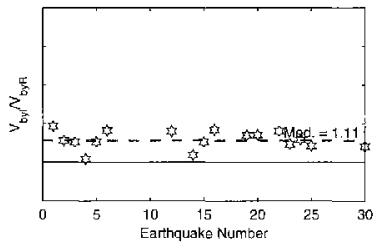

Figure 6. Ratio of peak inertial and structural base shears for North Hollywood hotel: (a) Longitudinal direction and (b) transverse direction.

however, much smaller: the median ratio is from 1.07 (Figure 6a) to 1.11 (Figure 6b). Therefore, it may be expected that the inertial force will exceed the structural base shear in the median by about $5 \%$ to $10 \%$.

The results presented in Figure 7 for the Los Angeles building show that the median value of the ratio varies from 1.07 (Figurc $7 \mathrm{a}$ ) to 1.22 (Figure $7 \mathrm{~b}$ ) implying that the inertial base shear exceeds the structural base shear in the median by $5 \% 1020 \%$. For an individual earthquake, the ratio can be as high as 1.7 in the longitudinal direction (Figure 7a) and 1.4 in the transverse direction (Figure $7 \mathrm{~b}$ ).

The discussion so far indicates that the median inertial base shear exceeds the structural base shear by $10 \%$ to $20 \%$. For an individual earthquake, however, the inertial base shear may excocd the structural base shear by as much as $70 \%$. Furthermore, the large discrepancy betwcen inertial and structural base shears occurs for ground motions with significant high-frequency content. Therefore, incrtial base shear should be used with caution as an estimate of the structural base shear in buildings with motions recorded during earthquake ground shaking.

(a)

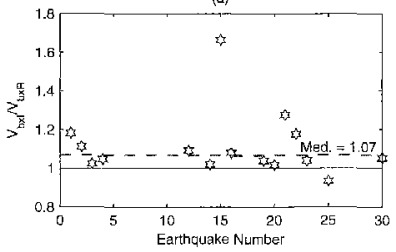

(b)

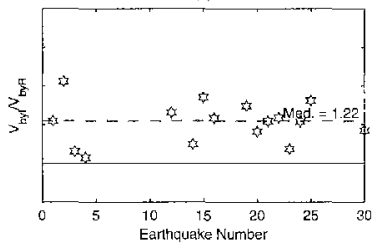

Figure 7. Ratio of peak inertial and structural base shears for L_os Angcles building: (a) Longitudinal direction and (b) transverse direction. 
Recently, I3emal (2010) also examined the ratio of incrtial and structural base shears for three buildings: a 6 -story commercial building in Burbank, a 10 -story residential building in San Jose, and a 13-story commercial building in Sherman Oaks. The results presented for these three buildings in Bernal (2010) also confirm the above-noted findings in this paper.

\section{CONCLUSIONS}

This investigation examined if the inertial base shear, defined as a summation of floor inertial forces above the building's base with the floot inertiai forces computed by multiplying the floor masses with the total floor accelerations, can provide an accurate estimate of the structural base shear which is equal to the sum of shears in all columns at the building's base. It was demonstrated that the median inertial base shear excecds the structural basc shear by 10 to $20 \%$. For individual earthquake ground motions, however, the inertial base shear may exceed the structural base shear by as much as $70 \%$. It was also demonstrated that the large discrepancy between incrtial and structural basc shears occurs for ground motions with significant high-frequency content. Therefore, inertial base shear should be used with caution as an estimate of the structural base shear for individual ground motion.

\section{ACKNOWLEDGMENT}

This investigation is supported by the Califomia Department of Conservation, California Geological Survey, Strong Motion Insirumentation Program, Contract No, 1007-907. This support is gratefully acknowledged. The author would also like to acknowledge the support provided by Professor Graham Powcll on the implementation of Perform $3 D$ and by Dr. Charles Chadwell and Karen Nishimoto on the use of Xtract.

\section{REFERENCES}

American Society of Civil Engineers (ASCE), 2000. Prestundard and Commentary for the Seismic Rehabilitation of Buildings, Report No. FEMA-356, Building Seismic Safety Council, Federal Fmergency Management $\Lambda$ gency, Washington, D.C.

Bernal, D., and Nasseri, A., 2009. Schemcs for reconstructing the seismic response of instrumented buildings, Proceedings of SMIPOS Semindr on Utilization of Sirong-Motion Data, Strong Motion Instrumentation Progran, CDMG, Sacramento, CA.

Bcmal, D., 2010. Estimation of the Scismic Responsc of Buildings, Report on Data Interpretation Project, Department of Conservation, Califomia Geological Survey, Strong Motion Instrumentation Program, CDMG, Sacramento, $\mathrm{C} \Lambda$.

Computers and Stuctures, Inc. (CSI), 2006. Perform3D: Nonlinear Analysis and Performance Assessment for $3 d$ Structures: Version 4, Computers and Structurcs, Inc., Berkeley, CA.

Goel, R. K., 2005. Evaluation of modal and FFMA pushover procedures using strong-motion records of buildings, Earthquake Specira 21, 653684 .

Goel, R. K., 2009. Setsmic Analysis of Buildings to Recorded Motions, Data Ltilization Rcport California Strong Motion Instrumentation Program, Report No. CP/SEAM 09/01, Caililornia Polytechnic State University, San Luis Obispo, CA, http://digitalcommons.calpoly. edu/cenv_fac $/ 186 /$. 
Goel, R. K., and Nishimoto, K., 2009. Seismic analysis of buildings to recorded motions: Modcling and sofiware challenges, in Proceedings of SMPO9 Seminar on Utilization of StrongMotion Data, Strong Motion Instrumentation Program, CDMG, Sacramento, CA.

Goel, R. K., 2010. Base Shear Estimated from Floor Accelerations and Column Shears, Report No. CP/SEAM 2010/01, California Polytechnic State University, San Luis Obispo, CA, http://digitalconmons,culpoly.edu/cenv_fac/ $185 /$.

Jennings, P. C., 1997. Use of strong motion data in carthquake resistant design, in Proceedings of SMP97 Seminar on Ltilization of Strong-Motion Data, Strong Motion Instrumentation Program, CDMG, Sacramento, CA.

Limongelli, M. P., 2003. Optimal location of sensors for reconstruction of seisunic response through spline function intorpolation, Earthquate Engineering and Structural Dynamics 32, $1055-1074$.

Naeim, F, 1997. Performance of Extensively Instrumenled Buildings During the January 17. 1994 Northridge Earthquake: An Interactive Information System, Report No. 97-7530.68. John A. Martin \& Associates, Los Angeles, CA.

Naeim, F., 1998. Performance of 20 Extensively-Instrumented Buildings during the 1994 Northridge Earthquake," The Structural Design of Tall Buildings 7, 179-194.

Naeim, F., Lee, H., Bhatia, H., Hagic, S., and Skliros, K., 2004. CSMIP instrumented building response malysis and 3-D visualization system (CSMIP-3DV), in Proceeding of SMIPO4 Seminar on Uilization of Strong-Motion Data, Strong Motion Instrumentation Program, CDMG, Sacramento, CA.

(Reccived 21 April 2010; accupted 8 December 2010) 